\title{
Crítica genética: o que interpretar?
}

\author{
Claudia Amigo Pino*
}

\section{Resumo}

Este texto tem como objetivo revisitar o livro Escrever sobre escrever. Uma introdução crítica à crítica genética (PINO e ZULAR, 2007), mostrando uma nova visão histórica da disciplina e, principalmente, novas propostas interpretativas. Para isso, lançamos mão de discussões recentes dentro da crítica genética francesa e tentamos um dialogar com as propostas teóricas de Foucault, Bourdieu e Maingueneau, procurando uma visão de gênese mais ampla e menos descritiva. No final, recorremos a alguns exemplos de escritores brasileiros, como Machado de Assis, Mario de Andrade e Guimarães Rosa, para mostrar particularidades dos arquivos locais e as suas possibilidades de interpretação.

Palavras-chave: Crítica genética. Manuscritos. Foucault. Bourdieu. Maingueneau.
Sete anos se passaram desde a publicação do livro Escrever sobre escrever. Uma introdução crítica à crítica genética (PINO e ZULAR, 2007) que pretendia introduzir uma crítica genética (disciplina que estuda o processo de criação literária) mais ampla, centrada no estudo das práticas de escrita. Nesse tempo, a crítica genética francesa lançou novas discussões e a crítica genética brasileira procurou novos caminhos interpretativos, em alguma medida, relacionados com as propostas do livro publicado em 2007.

Aqui, pretendemos revisitar essas propostas a partir dessas discussões e pesquisas mais recentes. Para isso, assim como no livro, faremos uma discussão sobre o surgimento da disciplina, desta vez mais centrada na tradição da qual ela se origina. A crítica genética não foi uma revolução nos estudos literários: a reflexão sobre a gênese do texto

\footnotetext{
Professora Associada, Pós-graduação em Estudos Linguísticos, Literários e Tradutológicos em Francês, Universidade de São Paulo (USP).
}

Data de submissão: jul. 2014 - Data de aceite: ago. 2014 http://dx.doi.org/10.5335/rdes.v10i2.4196 
é antiga e remonta ao início da crítica literária. Para discernir o nosso objeto e propor interpretação, precisamos entender essa tradição, quais são os seus impasses e, é claro, criar uma distância e relação a ela. Depois, voltaremos às primeiras definições da crítica genética e às primeiras discussões das que foi objeto, para em seguida entrar nas críticas que tem recebido na França e no Brasil. Então, tentaremos voltar às propostas de nosso livro crítico, e fazê-las dialogar com as noções de campo literário, de Pierre Bourdieu e de contexto discursivo, de Dominique Maingueneau. Finalmente, propomos algumas reflexões preliminares sobre processos de criação de obras brasileiras, a partir dessa ideia de uma crítica genética mais ampla.

Mas estamos muito longe ainda do Brasil e dessa crítica genética, começaremos desde muito antes, desde antes que alguém tivesse pensado em guardar algum manuscrito...

\section{Por um lado a recepção, por outro a produção}

O estudo da criação literária não é recente, surgiu somente um pouco depois do início da crítica literária, no Século XIX. Mas antes de entender esses primórdios genéticos, é preciso lembrar que a crítica literária surge em vários países ao mesmo tempo, com visões opostas, tomando um caminho semelhante ao da própria produção literária. Enquanto, no início do século, o romantismo se consolidava no que hoje é Alemanha e na Inglaterra, a França reafirmava a escrita sob regras característica do classicismo. A divisão geopolítica da Europa se refletia nas escolhas e na aceitação dos escritores. ${ }^{1}$

Assim como a literatura, a crítica literária também tomava rumos opostos nos países inimigos: enquanto na Alemanha o foco era a recepção literária, na França, os esforços se concentravam em entender a produção. Para citar um exemplo alemão, reproduzo a seguir um trecho de Conversa sobre poesia, um dos textos inaugurais da teoria do romantismo alemão; ali, F. Schlegel assinala que a crítica deve ser sempre uma ampliação da literatura, ou um gesto de amor do leitor pelo texto.

Por isso o poeta não deve satisfazer-se com o legado, em obras duradouras, da expressão da poesia que lhe é inata e característica. Ele precisa sempre almejar uma ampliação de sua poesia e de sua visão de poesia, aproximá-las do mais alto que é possível na terra; assim, estará se esforçando para associar-se ao grande todo da maneira mais definida, mais determinada - pois a mortal generalização opera justamente ao contrário.

Ele o conseguirá, quando tiver encontrado o centro na comunicação com aqueles que também o encontrarem, vindo de outros caminhos e de suas maneiras. $O$ amor precisa ser correspondido, precisa de um contra-amor. (SCHLEGEL, 1994, p. 30-31, grifo do autor)

Como podemos observar, a crítica basicamente se caracterizava, para Schlegel, por não se satisfazer com a literatura tal como ela é. A obra chama o leitor a mudá-la, ampliá-la, transformá-la em 
outra coisa. Não há busca de um texto original, nem qualquer preocupação em entender o talento do escritor ou a origem da obra: o foco estava na recepção da obra.

Na França, a crítica literária se desenvolve de forma mais tardia do que na Alemanha, já que a prática crítica é própria do romantismo. ${ }^{2} \mathrm{O}$ primeiro grande crítico francês torna-se conhecido a partir dos anos 20, depois do Congresso de Viena e do estabelecimento da paz entre França, Alemanha e Inglaterra. Trata-se de Charles Sainte-Beuve, que desenvolveu um método hoje completamente desprezado pela academia: o método biográfico de análise literária, que propunha tentar entender a qualidade da obra pelo caráter moral do escritor. Por isso, ele alegava que era muito difícil criticar autores vivos, já que o julgamento moral podia trazer alguns problemas para o crítico:

É sempre fácil julgar um escritor, mas não igualmente fácil julgar um homem. (...) Oh! Como um homem é difícil de conhecer, mesmo quando esse homem não somos nós, quando ele é simplesmente um outro! Quando se busca o homem no escritor, o elo entre caráter e talento, não saberíamos estudá-lo bem, enquanto esse objeto ainda vive (SAINTE-BEUVE, 1992, p.136-137).

Para conhecer esse "caráter" do escritor, era necessário efetuar uma pesquisa biográfica: conhecer seus amigos, suas amantes, seu lugar de trabalho, seus ancestrais. Porém, é importante destacar que Sainte-Beuve não se surpreendia com o resultado de sua pesquisa: se a obra era julgada "boa", o caráter do escritor necessariamente seria bom também. O que demonstra a fragilidade de sua pesquisa, muitas vezes fundada em histórias ouvidas informalmente ou "intuições" do crítico.

Ao contrário do romantismo alemão, seu propósito não era explorar o que acontecia depois da escrita obra, mas o que acontecia antes; neste caso, a constituição do caráter do escritor. Tratava-se de um método centrado na produção. Porém, ele não propunha realmente fazer um estudo dessa produção da obra: seu propósito era apenas confirmar uma informação já dada: a produção não era um objeto de conhecimento, mas uma forma de entender, ou mesmo de certificar a obra. (Em um contexto mais amplo, é possível afirmar que essa forma de encarar o objeto literário inaugura a crítica de tradição francesa, que tenta sempre explicar os fenômenos literários invocando a sua origem - seja ela biográfica, histórica ou mesmo psicanalítica. Ora, não é coincidência que aqui, para explicar a crítica genética, eu tenha voltado à tradição na qual ela que insere. Isso atesta, de certa forma, uma tradição francesa nesta argumentação.)

Mas houve alguns momentos de paz entre os dois países. O romantismo trouxe, para os dois países, a valorização do nacional e de seu patrimônio.Tanto na França quanto na Alemanha começa a surgir a necessidade de cultuar seus escritores e, também, de preservar seus documentos e relíquias. Eis como dois ícones do romantismo, Goethe e Victor 
Hugo, transformam-se em autores-símbolo em relação ao tratamento de seus manuscritos: Goethe foi a primeiro a catalogar seu arquivo, enquanto Victor Hugo, o primeiro a doar seus manuscritos a uma instituição pública. Essa valorização dos manuscritos enquanto tesouro nacional permitiu que, na Alemanha, fosse desenvolvida uma disciplina dedicada especificamente ao deciframento e ao entendimento desse tipo de documentos: a filologia (GRESSILLON, 1994, p. 83).

Ao longo do século XIX, a crítica francesa de tradição "produtiva" vai incorporar e valorizar esse conhecimento próprio da filologia. Mas para isso, foi necessária uma mudança de "suporte" da crítica literária. Enquanto antes ela era desenvolvida especialmente em colunas e artigos curtos de jornais, a partir de 1870 ela também ocupa o lugar das universidades, transformando-se em tema de teses e artigos de revistas especializadas. Nesse novo lugar, a pesquisa precisa ser mais "séria" e incorporar métodos das ciências humanas. E assim surge a análise historiográfica, também com foco na produção literária, como a crítica biográfica, mas com algumas diferenças.

A pesquisa biográfica faz-se de forma menos intuitiva, incluindo pesquisa bibliográfica e de campo, e juntam-se a ela estudo sobre o meio social do escritor e a análise de manuscritos, por meio do conhecimento da filologia. Esse novo saber permitia um conhecimento maior sobre a produção, embora o foco sempre estivesse no próprio texto. Além disso, a análise dos manuscritos também pretendia estabelecer o "verdadeiro texto" assinado pelo autor, descartando assim possíveis mudanças feitas pelos editores (LANSON, 1965, p. 42-46). É possível dizer que nesse momento nascia a crítica genética?

Segundo seus fundadores, não. Essa foi uma discussão antiga, travada no início dos anos 90. Nesse momento, o crítico Michel Espagne e Graham Falconer, entre outros, afirmavam que muito daquilo que a crítica genética trazia de inovação já tinha sido desenvolvido pela crítica historiográfica, por exemplo, nos textos do próprio Lanson. Já Jean-Louis Lebrave rebateu estas críticas afirmando que o objeto da crítica genética é completamente outro:

\begin{abstract}
A pesquisa atual dos geneticistas, pelo contrário, inscreve-se em um contexto mais amplo, onde o interesse do público não se dirige apenas ao autor e ao que testemunha sua genialidade, mas para o próprio objeto manuscrito e os processo dos quais porta os vestígios (LEBRAVE in ZULAR, 2002, p. 145).
\end{abstract}

Dessa forma, embora houvesse análise de manuscritos na análise historiográfica, não se podia de crítica genética propriamente dita, já que o foco não estava na produção: os manuscritos serviam para auxiliar a leitura do texto e também para validá-lo. Mas para entender bem essa separação entre o olhar historiográfico-filológico e a crítica genética, temos que voltar ao nosso olhar geopolítico sobre a crítica. Como 
foi afirmado no início do texto, a crítica alemã centrava-se na recepção literária e tinha como objetivo ampliar a obra, ir em direção oposta à obra. A crítica de tradição francesa centrava-se, pelo contrário, na produção literária, e não tinha como objetivo ampliar a obra, mas entendê-la, certificá-la, ficar sempre mais e mais perto da obra. Ora, a crítica genética surge como uma forma de aliar essas duas tradições.

\section{A crítica genética: entre a recepção e a produção}

A crítica genética surge em 1968 , um ano marcado pela revoltas universitárias. Nada menos propício naquele momento que se afiliar à grande linha dominante na tradição universitária francesa: a historiografia. Se naquele momento surgia algo novo, só tinha possibilidade de sobrevivência se negava a tradição vigente. Além disso, há um detalhe na criação da crítica genética que não pode passar desapercebido: ela surge de um grupo de pesquisadores dedicados a estudar os manuscritos de um poeta do romantismo alemão, Henrich Heine.

Assim, trata-se de unir um olhar sobre a produção a um desejo de ampliação, próprio dos estudos da recepção. Só que nesse caso, o olhar não é sobre a obra literária, mas sobre a própria produção. $\mathrm{Ou}$ seja, nos estudos genéticos, o estudo dos manuscritos não serve para esclarecer ou certificar a obra final, mas para criar uma reflexão sobre o processo de criação.
Nessa reflexão, não se chegará ao processo de criação que realmente aconteceu (que não pode ser mais que uma utopia), mas a uma nova construção. Dessa forma, assim como no romantismo alemão, a crítica genética não propõe ficar mais perto da obra, mas, pelo contrário, uma ampliação, uma nova construção:

[O crítico genético] constrói (...) hipóteses sobre os caminhos percorridos pela escrita e sobre as significações possíveis desse processo de criação que Proust, dando continuidade a Leonardo da Vinci qualificou de cosa mentale. É nessa construção que é necessário ser o mais "Dupin" possível, "poeta e matemático", sensível tanto ao traço físico e fugitivo da mão que às interferências e efeitos múltiplos da textualidade in statu nascendi. E é aí também, nesse espaço amplamente inexplorado, que reside a possibilidade de descobertas: O que é escrever? Como se escreve? Como a analisar a língua escrita quando o documento superpõe o paradigmático ao sintagmático? O que é a escrita literária? Qual é o estatuto teórico desses proto-textos? Eles fazem parte da literatura? Há acontecimentos na escrita que marcam a invenção? (GRÉSILLON, 1994, p. 15 , grifo do autor).

Já pela primeira frase da citação desse texto de referência para os geneticistas, vemos que o propósito da crítica genética não é reconstituir o processo de criação original, mas construir algo novo (hipóteses), a partir do qual surgem novas perguntas sobre a criação de forma geral.

Mas essa paz entre produção e recepção tem também seus impasses. Mesmo se produção não está ali para se aproximar da obra, mas para criar novas perguntas e novas reflexões, os geneticis- 
tas franceses fazem questão de reforçar essa necessidade de suporte material do manuscrito. Assim, se por um lado, a crítica genética implica um olhar receptivo (de distanciamento) em relação à obra, ela também obriga a uma aproximação à obra, ou, mais precisamente, aos seus documentos de processo:

O objeto dos estudos genéticos é o manuscrito de trabalho, aquele que contém os vestígios de um ato, de uma enunciação em marcha, de uma criação se fazendo, com seus avanços e seus brancos, seus acréscimos e suas rasuras, suas pulsões descontroladas e suas retomadas, seus excessos e suas faltas, suas despesas e suas perdas (GRESILLON, 1994, p. 33).

O estudo da gênese, para os primeiros geneticistas franceses, gira sempre em torno do manuscrito. É claro que o objetivo é se referir à crítica genética de forma ampla (afinal, a crítica genética se pergunta: o que é escrever? como se escreve?), mas só é possível fazê-lo a partir do documento. Em 2010, em uma nova discussão de questões teóricas fundadoras da crítica genética, este elemento foi ainda reforçado: a ideia é discutir a criação, mas isso só pode ser feito a partir do "portal" do manuscrito, que, ainda por cima, deve ser inédito.

A abordagem genética não constitui simplesmente um novo ponto de vista crítico sobre as obras e seu contexto, mas repousa, em primeiro lugar, sobre a existência de uma jazida - às vezes considerável - de documentos inéditos que é necessário encontrar, classificar e interpretar para fazê-los inteligíveis. São esses documentos, até agora ausentes do debate, que constituem o acesso ao universo dos processos cuja obra é o seu fim: um portal (BIASI, 2010, p. 166, grifo do autor).
Ora, essa postura contraditória em relação à tradição a qual pertence a crítica genética tem colocado os pesquisadores dessa linha em um dilema interpretativo. Por um lado, há um chamado a refletir, pensar a criação de forma ampla. Por outro lado, é preciso se ater à existência desses documentos e aos índices dados por eles. Assim, a crítica genética conta com uma grande tarefa descritiva, que muitas vezes inibe a prática interpretativa. Essa é uma constatação dos próprios fundadores da crítica genética, que não veem ali um problema. É o caso de Pierre-Marc de Biasi, em seu texto de 2010, defende que a disciplina não pode ser mais considerada "crítica", mas simplesmente "genética", já que seu objetivo não passa, de fato, por interpretar:

Começar, o quanto for praticável, por não interpretar: eis o que distingue a pesquisa genética de todas as outras formas de abordagem crítica das obras. Qualquer que seja a natureza dessa obra, o essencial da pesquisa reside nessa conversão do olhar: não tanto o resultado em si mas o processo do qual ele deriva e o anima (BIASI, 2010, p. 167).

Essa defesa da não interpretação leva, necessariamente, a deixar para trás a tradição romântica, que previa ampliar a obra ou refletir sobre a obra. Mesmo se aqui não se trata da obra em si, mas do seu processo de criação, essa reflexão é muito limitada pelo documento; no jogo entre o afastamento e a aproximação ao texto, a aproximação parece ter levado a melhor. 


\section{Fecha-se a porta e a interpretação entra pela janela}

Enquanto a crítica genética francesa colocava a interpretação em suspenso, alguns pesquisadores no Brasil e também na França começam a encontrar problemas nesse modelo descritivo da crítica genética e a esboçar novas possibilidades de conjunção entre produção e recepção (ou entre gênese e interpretação).

As razões pelas quais o Brasil se destaca nessa procura por novas possibilidades estão ligadas às limitações do trabalho com documentos e arquivos no país. Enquanto a França conta com bibliotecas que centralizam a compra e a conservação de manuscritos (como a Biblioteca Nacional da França), no Brasil os manuscritos de escritores encontram-se dispersos em pequenos e médios acervos, que raras vezes têm recursos para adquirir documentos. Assim, o pesquisador que deseja estudar o processo de criação de um determinado autor, encontra-se com o problema de não contar exatamente com uma "jazida considerável de documentos inéditos", como recomenda Pierre-Marc de Biasi.

Além dessa restrição documental, o desenvolvimento institucional das pesquisas genéticas no Brasil impôs também uma maior necessidade de desenvolvimento teórico. Aqui não há um Instituto dedicado aos textos e manuscritos modernos, como o ITEM, na França, que reúne os pesquisadores em torno de autores e corpus específicos e onde é possível passar manhãs inteiras discutindo a transcrição de uma frase e o uso de uma determinada vírgula. No Brasil, os estudos genéticos são realizados dentro de Universidades e, em grande parte, por estudantes com interesses bem diversos, reunidos em grupos heterogêneos. Nesse contexto, a descrição torna-se especializada demais: são raros os casos em que é possível um diálogo sobre a descrição de documento. ${ }^{3}$ Para que efetivamente haja diálogo, a comunidade acadêmica tem preferido discussões conceituais mais amplas, que extrapolam o documento. Por isso, há um estranhamento em relação aos manuais e especialmente às últimas discussões na França. Um exemplo dessa postura são os livros de dois grandes introdutores da crítica genética no Brasil: Cecília Almeida Salles e Philippe Willemart, que têm discutido corpora variados, procurando explicações genéricas sobre a criação, que podem ser aplicadas a diversos corpora. ${ }^{4}$

Porém, o chamado a uma crítica genética mais interpretativa não vem apenas do Brasil. Na própria França, alguns pesquisadores que trabalham com manuscritos (mas não são contratados pelo ITEM) têm manifestado seu incômodo em relação a essa excessiva concentração no documento. É o caso de Philippe Hamon, conhecido pelas obras sobre a descrição e a imagem no realismo francês. Ele cita, por exemplo, o caso do escritor naturalista Émile Zola, que conta com uma enorme jazida de documentos pesquisa, planos da narrativa, descrição 
de personagens, mapas - mas que têm pouquíssimas informações sobre a gênese estilística das obras. Há também uma ausência de marcas nos mansucritos relativas ao "tom" do texto (irônico? Sério?), que são chaves para o impacto final da obra. Se nos restringirmos apenas aos documentos deixados por Zola, estudaremos o processo de criação de livros aparentemente referenciais, talvez pequenas etnografias da burguesia francesa, que são muito distantes dos textos que ele realmente escreveu, repletos de imagens, rimas narrativas, cores, texturas.

O primeiro ponto [de insatisfação em relação à crítica genética] está ligado a uma certa - e talvez excessiva, especialização dos objetos na crítica genética.Muitos, e aparentemente majoritários, pelo menos pelo que eu pude conhecer, são os estudos genéticos que se interessam pelos sistemas textuais que se geram, seja por expansão e declinação de um paradigma latente (campo lexical, campo semântico, campo temático), ou seja, sistemas descritivos (o conjunto da "listagem"), seja por concatenação transformacional de um sistema lógico-semântico, ou seja, sistemas narrativos (as "histórias"). Talvez porque, nos dossiês preparatórios dos escritores estudados, os geneticistas encontram majoritariamente, logo de partida e se apresentando como tal, dois tipos de "textos": de um lado as "listas" (listas de títulos, de datas, se personagens, de nomes próprios, termos técnicos de "palavras", de obras a serem lidas, etc.), de outra parte os "planos", resumos e roteiros (e esboços de roteiros). Em contrapartida, os outros sistemas textuais "globalizantes", por exemplo os sistemas poéticos (no sentido jakobsoniano do termo), os sistemas rítmicos, os sistemas argumentativos, e os sistemas do diálogo, são claramente menos estudados em seus cadernos de esboços respectivos e em seus modos (específicos ou não) de germinação.
Talvez isso se deva à submissão às vezes rígida de uma certa genética ao estudo de elementos "locais", isoláveis, facilmente autonomizáveis (por exemplo, uma descrição de paisagem, uma sequência narrativa, um retrato de personagem...), ao mesmo tempo nos manuscritos e na manifestação textual dos textos (HAMON, 2010, p. 65, grifo do autor).

A crítica de Hamon tem como alvo, a submissão ao que nos dizes os documentos. Para pensar a criação, é necessário levá-los em conta, mas também ir além. Muitas vezes, eles não funcionam como portal e até fecham as portas para um pensamento mais amplo sobre o processo de criação. Mas, se não devemos nos ater à descrição do documento, o que interpretar?

\section{$\mathrm{O}$ que interpretar: perspectivas}

Em 2007, Roberto Zular e eu propusemos relacionar a pesquisa com manuscritos às perguntas colocadas por Michel Foucault em A arqueologia do saber para o estudo dos enunciados. Um "enunciado" para Foucault não poderia ser uma frase num documento, ou mesmo numa obra literária: ele se refere a formas de estabelecidas dentro de uma prática discursiva determinada. Por exemplo, no âmbito da crítica literária, nós lidamos com os enunciados "autor", "obra", "estilo", "estrutura”, etc. Mesmo se, em certa medida, aqui eu tenho tentado entender a origem de alguns enunciados próprios da crítica genética ("produção" ou "ampliação", por exemplo), não era essa nossa proposta inicial. Nós propomos 
transpor as questões colocadas por Foucault para o estudo dos enunciados para refletir sobre conjuntos de documentos:

Dizer que os enunciados são remanentes não é dizer que eles permanecem no campo da memória ou que se pode reencontrar o que queriam dizer, mas sim que se conservaram graças a um certo número de suportes e de técnicas materiais (de que o livro não passa, é claro, de um exemplo), segundo certos tipos de instituições (entre muitas outras, a biblioteca) e com certas modalidades estatutárias (que não são as mesmas quando se trata de um texto religioso, de um regulamento de direito ou de uma verdade científica). Isso quer dizer, também, que eles estão investidos em técnicas que os põem em aplicação, em práticas que daí derivam em relações sociais que se constituíram ou se modificaram através deles (FOUCAULT, 2008, p. 140, grifo do autor).

Assim, a nossa ideia era tentar entender um conjunto de manuscritos sobre determinada obra dentro do seu contexto de produção, circulação e recepção. Mais especificamente, isso significa entender, em relação à produção, quais foram as práticas e suportes materiais de sua produção: qual a tecnologia da escrita? $\mathrm{O}$ que ela nos obriga a escrever?(por exemplo, hoje, os processadores de texto) Qual era a disponibilidade dos suportes (por exemplo, papel). Como se ensina a escrita nas escolas, nas universidades? Já em relação à circulação, é necessário se perguntar como esses documentos chegaram ao pesquisador? Quem os adquiriu/ legou? Por que eles fazem parte (ou não) do acervo de uma biblioteca? Por que o escritor decidiu conservá-los? Finalmente, sobre a recepção, nunca podemos deixar de ter em vista por que a nossa instituição sedia uma pesquisa sobre manuscritos, por que ela é financiada (ou não), e qual é o interesse específico do pesquisador em estudar um determinado processo de criação (PINO e ZULAR, 2007). Essas perguntas nos ajudam a encontrar novos caminhos de interpretação, porém elas ainda não dão conta de muitos aspectos da produção da obra literária.

A criação literária não é produto de apenas um escritor, como a própria crítica genética tem levado a pensar, considerando os estudos de processos de criação centrados na figura do autor. ${ }^{5}$ Há uma multiplicidade de sujeitos empenhados não só na produção da obra, mas também no fato de ela ser dotada de certo valor. E ninguém estudaria os manuscritos de uma obra literária se ela não tivesse esse valor reconhecido pelo pesquisador e pelas agências de apoio. Essa é a visão do sociólogo Pierre Bourdieu, que também pode ser de grande ajuda na busca de um novo tipo de interpretação em crítica genética:

O produtor do valor da obra de arte não é o artista, mas o campo de produção enquanto universo de crença que produz o valor da obra de arte como fetiche ao produzir a crença no poder criador do artista. Sendo dado que a obra só existe enquanto objeto simbólico dotado de valor se é conhecida e reconhecida, ou seja, socialmente instituída como obra de arte por espectadores dotados da disposição e da competência estéticas necessárias para a conhecer e reconhecer como tal, a ciência das obras tem por objeto não apenas a produção material da obra, mas também a produção do valor da obra ou, o que dá no 
mesmo, da crença no valor da obra (BOURDIEU, 2002, p. 259, grifos do autor).

O manuscrito, assim, deve ser considerado como apenas um dos documentos que constituem a produção literária, o documento de apenas um dos implicados: o escritor. Além dele, estão incorporados aqueles que fizeram parte do sistema específico de produção: editora, jornal, site ou blog, por exemplo, e todos aqueles determinantes em conferir valor para esse produto: por exemplo, o editor, jurados de concurso literário e também o crítico ou a rede de críticos com a qual o escritor dialogava (conscientemente ou não) quando escreveu e apresentou a obra para uma editora. Esses sujeitos também geram documentos, como o arquivo de uma determinada editora (ofícios, catálogo, apresentação de livros, linhas editoriais, disposições internas), as anotações e textos de críticos e editores, e os testemunhos das relações entre eles (por exemplo, cartas ou entrevistas).

Essas propostas dão conta de muitos elementos do processo criativo que não podem ser interpretados a partir da observação dos manuscritos de trabalho, mas eles ainda não respondem completamente algumas das questões colocadas por Philippe Hamon, como "como interpretar a gênese estilística, ou a formação do tom" das obras literárias. A comunicação entre escritores e críticos pode nos ajudar a entender a escolha de certos procedimentos literários. Mas para uma discussão mais ampla, é necessário pensar a ceno-grafia, a rede de discursos na qual o autor se insere, de forma mais ampla. Para isso, é de interesse para a crítica genética dialogar com outro autor que pensou a gênese, mas a partir da análise do discurso: Dominique Maingueneau. Em $O$ contexto da obra literária, Maingueneau defende que a posição do escritor é bastante peculiar dentro do seu campo discursivo: ele é aquele que está sempre fora de lugar. Para que seja reconhecido o valor de uma determinada obra, é necessário que ela tome distância dos discursos ao seu redor. Porém, essa distância não é necessariamente dada pelo que está "dito" no texto:

Tanto no caso das obras literárias como no dos enunciados "comuns", tende-se a esquecer o contexto pragmático, a só ver o dito. Contudo, confronto entre esse dito e o ato de enunciação é uma dimensão essencial da obra literária: não apenas ela constrói um mundo, mas ainda deve administrar a relação entre esse mundo e o evento que seu próprio ato de enunciação constitui, o qual não pode ser simplesmente rejeitado para fora do mundo representado (MAINGUENEAU, 1993, p. 158, grifo do autor).

Dessa forma, podemos encontrar uma resposta possível à questão colocada por Hamon acima. O tom do texto é dado pela forma em como ele deve ser lido, não necessariamente por aquilo que está escrito e, por isso, é muito difícil encontrar a sua gênese nos manuscritos. Mas como interpretar essa distância produzida na leitura? Analisando o que ele chama de contexto enunciativo de uma obra literária, dado, por exemplo, pelas diversas posturas do autor em entrevistas, pela 
sua filiação literária a um movimento literário ou político, pela forma em como esse autor lê outros texto, além de outra infinidade de fenômenos ("é muito difícil estabelecer uma tipologia desses fenômenos", destaca Maingueneau). Assim, para interpretar a gênese de um texto, é necessário se perguntar por essa formação do contexto discursivo em que essa enunciação foi possível, o que é dado pelos estudos biográficos, históricos, discursivos, mas também pela análise da obra, que muitas vezes encena seu próprio contexto. ${ }^{6}$

\section{Uma interpretação possível}

O estudo em crítica genética propõe alguns desafios a mais do que os trabalhos em crítica literária que não levam em conta os manuscritos. Muitas vezes, é preciso transcrever centenas de fólios escritos com uma caligrafia incompreensível, ou passar tardes observando marcas d'água, medindo e pesando papeis, para poder estabelecer uma possível cronologia. A ideia de associar a essa tarefa um estudo das práticas de produção, circulação e recepção (Foucault), uma descrição do campo literário (Bourdieu) ou um estudo do contexto enunciativo (Maingueneau) pode parecer, à primeira vista, uma tarefa impossível.

Mas alguns esforços já vem sendo feitos nesse sentido, até porque estamos em uma nova fase dos estudos genéticos. Há quarenta anos atrás, muitos acervos não tinham sido localizados, muito me- nos catalogados ou transcritos. Hoje já contamos com muitos manuscritos em acervos, classificados, transcritos e, algumas vezes, publicados. Isso permite que pouco a pouco, alguns pesquisadores se sintam liberados desse esforço descritivo inicial e procurem interpretações mais amplas, que considerem os documentos de processo, mas que também analisem os acervos das editoras, os recortes críticos de um autor, a correspondência com outros escritores, os seus documentos de leitura.

É o caso da tese de doutorado de Mônica Gama, "Plástico e contraditório rascunho: a autorrepresentação de João Guimarães Rosa”, defendida em 2013, que discute a imagem do autor a partir dos seus recortes de textos críticos de jornais, dos arquivos da editora José Olympio, das entrevistas publicadas, da correspondência, dos manuscritos e também da encenação das instâncias de escrita e recepção nas próprias obras. Não se trata de uma tese de sociologia, apesar de tratar de diversas organizações sociais: seu objetivo é entender a gênese em um sentido amplo - a partir do contexto discursivo, das práticas produtivas, do campo literário no Brasil e também da análise de manuscritos preparatórios e da própria obra. É importante destacar que a pesquisadora não teve como objetivo discutir o processo de criação de um texto, mas a produção de toda a obra de Guimarães, a partir de um aspecto que perpassa vários livros: a autorrepresentação do autor (GAMA, 2013). No exemplo a seguir, vemos um dos documentos que ela analisou, os 
rascunhos da apresentação de Grande Sertão Veredas, que já se encontrava facsimilado em um livro sobre a editora José Olympio:

Figura 1: Apresentação de João Guimarães Rosa para Grande Serão: Veredas

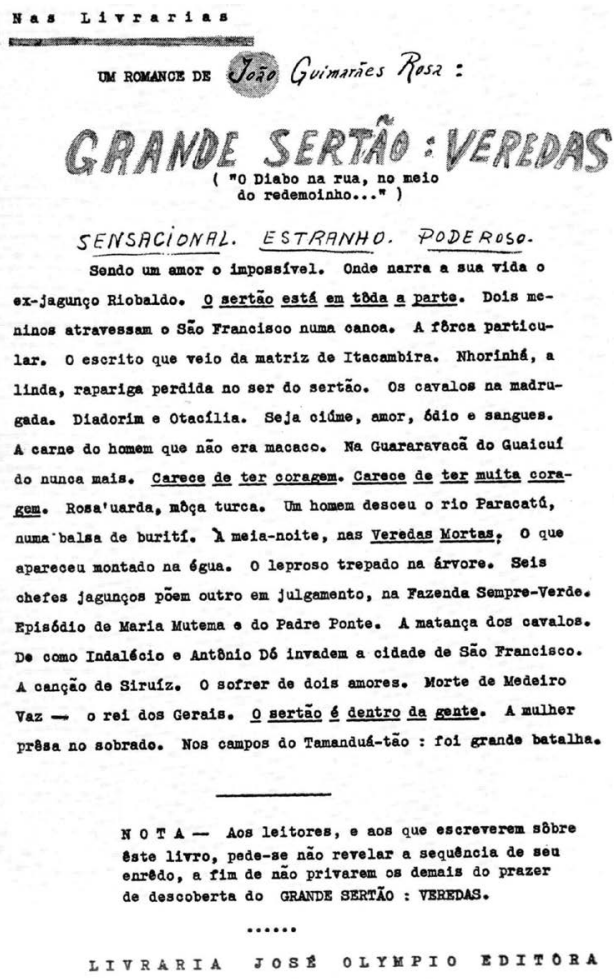

Fonte: Jose Olympio - O editor e sua casa. Org.: José Mário Pereira. Rio de Janeiro; Sextante, 2008. p.122.

Talvez esse pensamento da gênese de uma forma mais ampla ajude inclusive a refletir sobre alguns impasses do estudo do manuscrito brasileiro. Além do fato de não haver uma política pública central de aquisição e conservação dos arquivos literários no Brasil, é curioso que alguns dos mais importantes escritores brasileiros não contêm com uma importante "jazida" de manuscritos inéditos, como quer Pierre-Marc de Biasi. Um dos casos mais conhecidos, é o do talvez maior cânone da literatura brasileira: Machado. Apesar de alguns de seus manuscritos estarem disponíveis na Associação Brasileira de Letras, é conhecido que eles não apresentam mudanças significativas. É o caso dos manuscritos de Esaú e Jacob, mostrada em uma apresentação da pesquisa Luciana Antonini Schoepps no XI Congresso da Associação dos Pesquisadores em Crítica Genética (APCG). Ao contrário de Flaubert, amplamente estudado pela crítica genética francesa, o manuscrito desse romance de Machado conta apenas com uma versão manuscrita. Porém, como a pesquisadora observou em sua apresentação, não se trata de uma versão final: Machado reaproveitava as versões anteriores de seus textos: as rasuras ali encontradas correspondem a diversas campanhas de escritura. Essa hipótese é corroborada ao perceber a rasura constante da numeração de páginas e a presença de "colagens" de novos trechos, que "apagam" versões anteriores, como podemos observar no fólio reproduzido a seguir. É possível tentar construir alguns caminhos de escritura, porém trata-se de um caminho bastante limitado, pois só podemos observar algumas mudanças de palavras. Isso significa que não é possível discutir o processo de criação de Machado de Assis? Não, certamente podemos pensar em uma gênese mais ampla, que leve em 
conta o campo literário, a sua relação com a cenografia discursiva da época e com as práticas de escrita e circulação específicas da época. E tudo isso pode ser aliado ao estudo dessa única versão manuscrita, em que se diluem todos os tempos da criação. ${ }^{7}$

Figura 2: Manuscrito de Essaú e Jacob. Créditos: $\mathrm{F}^{\circ} 22$

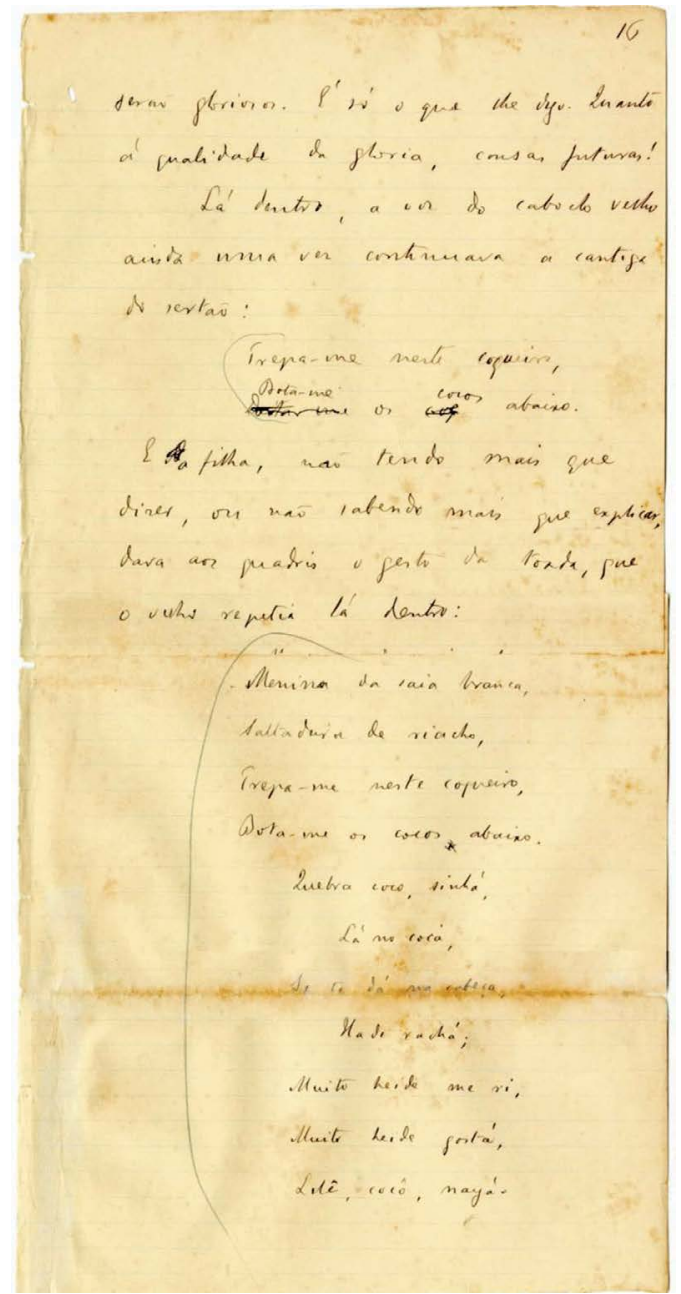

Fonte: Academia Brasileira de Letras, Arquivo Múcio Leão, Setor de Arquivo dos Acadêmicos. Disponí- vel em: <http://docvirt.com/docreader.net/docreader. aspx?bib=BVMachado\&pesq=>. Acesso em 20 nov 2012.

Essa inexistência de "jazida considerável" pode ser positiva e pode levar a uma discussão mais ampla de sua gênese: é o que vem acontecendo há décadas com o estudo da criação de Mario de Andrade. Como tem sido amplamente exposto pela equipe dedicada ao autor $n$ Instituto de Estudos Brasileiros (IEB), Mario de Andrade não guardava versões manuscritas dos seus textos publicados em vida: eles foram presenteados aos amigos, ou simplesmente deixados em editoras, como um resto. Porém, ele guardou manuscritos inéditos, documentos preparatórios de outros escritores, uma extensa correspondência, notas de leituras nas margens de seus livros e um grande fichário analítico composto de notas e reflexões variadas. Trata-se de um autor que oferece uma documentação escassa se quisermos descrever as diferentes etapas do processo criativo, porém, que tem uma documentação muito rica se quisermos pensar o contexto discursivo de sua produção. As dissertações e teses desenvolvidas no IEB dão conta dessa discussão sobre a sua criação sempre em relação com o discurso do outro: por exemplo, textos sobre manuscritos de outros escritores no acervo, ou sobre Mario de Andrade e as revistas francesas e o expressionismo alemão. Em uma recente dissertação de mestrado orientada pela professora Telê Ancona Lopez sobre o manuscrito inédito 
de "A gramatiquinha da fala brasileira", a pesquisadora Aline Novais de Almeida refere-se a esse fichário analítico como lugar de circulação desse contexto discursivo, onde é possível observar tanto a relação do escritor com a produção cultural com a qual ele dialogava, como o nascimento de novas obras (ALMEIDA, 2013). No exemplo reproduzidos a seguir, por exemplo, podemos observar as referências de Mário de Andrade sobre os filmes de Chaplin:

Figuras 3: Fichário analítico de Mário de Andrade

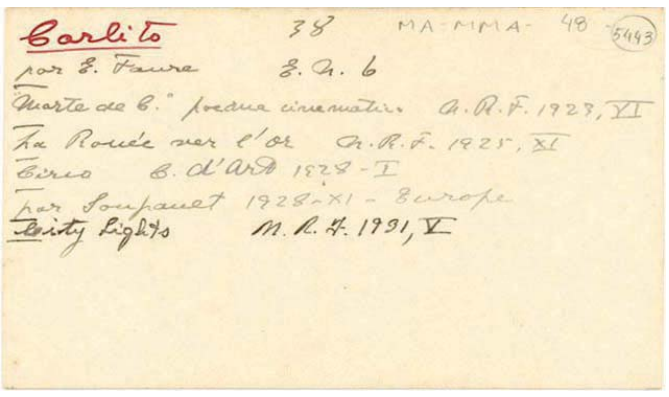

Fonte: Instituto de Estudos Brasileiros. Disponível em: <http://www.ieb.usp.br/marioscriptor/congressos/ carlito-ou-chaplin-da-criacao-ao-criador-um-exemplo-de-reelaboracao-textual-em-caras-de-mario. htmlhttp://www.ieb.usp.br/marioscriptor/congressos/carlito-ou-chaplin-da-criacao-ao-criador-um-exemplo-de-reelaboracao-textual-em-caras-de-mario.html>. Acesso: 08 ago. 2014.

Estes são apenas alguns exemplos de interpretações possíveis a partir da proposta de uma crítica genética mais ampla, menos descritiva e também mais democrática, já que considera a criação como um projeto coletivo, de um grupo de indivíduos, mas também de um tempo, de um contexto discursivo, de um campo intelectual, de uma prática de escrita.

\section{Genetic critic: what to interpret?}

\section{Abstract}

This text has the goal to revisit the book Write about write. A critical introduction to the genetic critic, showing a new historical vision of the discipline and, mostly, new interpretative proposals. For this, we bring recent discussions inside the french genetic critic and try to dialogue with Foucault, Bourdieu and Maingueneau theoretical propositions, looking for a wider genesis and less descriptive vision. In the end, we resort to some examples of brazilian writers, such as Machado de Assis, Mario de Andrade e Guimarães Rosa, to show particularities of the local files and its possibilities of interpretation.

Keywords: Genetic critic. Manuscripts. Foucault. Bourdieu. Maingueneau.

\section{Notas}

1 É importante destacar que essa divisão não é absoluta. Os irmãos Schlegel, na Alemanha, explicitam essa disputa ao afirmar que a literatura deve ser livre, e não regida por regras, como "afirmam na França". Porém, existiam escritores franceses que defendiam um novo tipo de literatura, mais centrada na prosa e no romance e ligada a uma tradição nacional, como, por exemplo, Madame de Staël. Porém, não existe ainda um movimento "romântico", que só existirá na França (de forma segmentada) vinte anos depois.

2 O movimento romântico tem a crítica como consequência porque pressupõe que não há regras para escrever. Assim, os tratados de poética não são suficientes para entender o texto literário: cada obra nova demanda uma nova reflexão. É nesse intuito que nasce a prática crítica entre 
o final do século XVIII e o início do século XIX.

3 Nesse contexto, devo destacar o trabalho do Projeto Brépols, na USP, que se dedica à transcrição dos cadernos de Proust e o Grupo Mário de Andrade, do IEB, que se dedica a transcrever e divulgar o acervo documental de Mário de Andrade.

4 É o caso dos livros Redes da criação (2006), de Cecília Almeida Salles, que tenta refletir sobre a aplicabilidade do pensamento em "rede" para descrever o processo de criação em várias artes (especialmente as artes plásticas) ou Psicanálise e teoria literária (2014), de Philippe Willemart, que tenta relacionar os manuscritos de Proust e Bauchau com operações próprias da psicanálise.

5 Como já foi dito, no Instituto de Textos e Manuscritos Modernos (ITEM), os diferentes grupos de pesquisa se reúnem em torno de acervos de autores específicos, como o grupo Émile Zola, Jean-Paul Sartre, Roland Barthes, Gustave Flaubert, Marcel Proust.

6 Maingueneau analisa exemplos de Flaubert e o próprio Zola, que tratam de escritores, leitores e das dificuldades de produção e intepretação de cada um.

7 A comunicação será publicada nos anais do congresso, cuja publicação está prevista para o ano de 2014. A autora gentilmente me cedeu o texto inédito da apresentação.

\section{Referências}

ALMEIDA, Aline Novais. Edição genética d'A gramatiquinha da fala brasileira. Dissertação (Mestrado em Literatura Brasileira. Disponível em: <http://www.teses.usp.br/teses/disponiveis/8/8149/tde-24102013-102309/ pt-br.phphttp://www.teses.usp.br/teses/disponiveis/8/8149/tde-24102013-102309/pt-br. php>. Acesso em: 8 ago. 2014.

BIAISI, Pierre-Marc.Pour une génétique généralisée: l'approche des processus à l'âge numérique. Genesis, 30. 2010. p. 163-175

BOURDIEU, Pierre. As regras da arte. Trad. de Maria Lúcia Machado. São Paulo: Companhia das Letras, 2002.
FOUCAULT, M. A arqueologia do saber. Forense Universitária: 2008.

GAMA, M. Plástico e contraditório rascunho: a autorrepresentação de João Guimarães Rosa. Tese (Doutorado em Literatura Brasileira) - Universidade de São Paulo. Disponível em: <http://www.teses.usp.br/teses/ disponiveis/8/8149/tde-07012014-094440/ pt-br.php>. Acesso em: 08 ago. 2014.

GRÉSILLON, A. Éléments de critique génétique. Paris: PUF, 1994.

HAMON, Ph. «Quelques questions à la génétique», Genesis, 30 । 2010, p. 65-68.

LANSON, G. Essais de méthode, de critique et d'histoire littéraire. Librairie Hachette, 1965. p. $42-46$

LEBRAVE, J. L. In: ZULAR, R. (Org.). Criação em processo. Ensaios de crítica genética. São Paulo: Iluminuras, 2002.

MAINGUENEAU, D. O contexto da obra literária. São Paulo: Martins Fontes, 1993.)

PINO, Claudia Amigo e ZULAR, Roberto. Escrever sobre escrever. Uma introdução crítica à crítica genética. São Paulo: WMF Martins Fontes, 2007.

SAINTE-BEUVE, C. Pour la critique. Paris: Gallimard, 1992.

SCHLEGEL, F. Conversa sobre a poesia. São Paulo: Iluminuras,1994. 